FEATURE ARTICLE

\title{
Reducing the Complexity Gap: Expanding the Period of Human Nurturance
}

\author{
L. DOUGLAS KIEL \\ University of Texas at Dallas (USA)
}

\begin{abstract}
Socio-techno-cultural reality, in the current historical era, evolves at a faster rate than do human brain or human institutions. This reality creates a "complexity gap" that reduces human and institutional capacities to adapt to the challenges of late modernity. New insights from the neurosciences may help to reduce the complexity gap. This paper argues that an extension of the period of human nurturance is one element that may serve to reduce the complexity gap. The argument herein is a synthesis of a variety of literatures that serve to support the notion of rethinking how long humans must be nurtured and educated.
\end{abstract}

Increasing complexity is a fundamental aspect of both biological and social evolution. While adaptation is necessary for biological and social systems to survive, we can observe a general progression of increasing complexity in the evolution of species and social systems. In short, species have evolved from single cell organisms to the wondrous animal Homo Sapiens Sapiens while human societies have evolved from simple hunter-gatherer groups to contemporary complex nation states in an increasingly globalized world.

From the social systems perspective, the increasing complexity of human systems creates distinct challenges for both social systems and individuals. In particular, we can observe that the rapidity of the increase in social complexity in the contemporary world outpaces the ability of any one individual to make sense of, and to perhaps adjust to and cope with the challenges of emerging realities. Complex societies simply seem to change and increase 
complexity at a rate much faster than the capabilities of any one individual. The challenge of the complexity gap concerns, at the most basic level, rates of change.

Technological and socio-cultural systems in the current period of late modernity change at a pace faster than that of either individuals or of the vast majority of human institutions. The human brain, clearly a complex system (Gazzaniga, Doron \& Funk, 2010) comprised of nonlinearities, network dynamics and surprises, evolves but at a much slower rate than sociotechno-cultural systems under the conditions of late modernity. The many brains of networked social systems simply create a reality that produces complexity in all of its manifestations at a faster rate than individual brains evolve.

Human institutions, from social institutions such as marriage to human politicoeconomic organizations, are stabilizing elements in society. Institutions serve to stabilize relations between citizens, organize means of production and allocate scarce resources. The stabilizing mission of institutions generally predominates even in the face of socio-technocultural pressures for change.

The differing rates of change between socio-techno-cultural systems and that of the human brain and of human institutions create a fundamental challenge for humanity. The fundamental challenge to humanity that is created may be labeled the complexity gap. The rate of change, or evolution, of socio-techno-cultural systems in late modernity increases at a pace that the human brain and human institutions cannot match. Thus, we live in a world in which the gap between socio-techno-cultural reality constantly increases relative to the evolutionary capabilities of human brains and human institutions. Attempting to reduce this gap is a fundamental challenge for humanity.

One effort to reduce the complexity gap involves efforts to create improved synchrony between an evolving reality and human capabilities and institutions. New insights in the neurosciences may provide a means for partially reducing the complexity gap. These insights, of relevance here, concern the age at which the human brain reaches maturity. Rethinking when the brain reaches maturity and what this means for human development and education may be critical to improving the synchrony between reality and individual and institutional level responses. Extending the period of human nurturance, beyond adolescence, may be one means for better matching a complex reality with human brain development. This paper attempts to establish a need for extending the period of human nurturance.

This synthesis is comprised of four sections. First, the nature of the current complexity gap is detailed at both the individual and institutional levels. A second section explores the nexus of the individual level and institutional challenges as it now exists. The third section of the paper details the proposed expansion of the period of human nurturance. The paper concludes with a recognition of the challenges and prospects of extending the period of human nurturance.

\section{The Nature of the Problem}

\section{Individual Level}

Scholars from a variety of perspectives and disciplines have attempted to explore the complexity gap (Nicholson, 2000; Van Vugt, 2012). One of the dominant perspectives in this 
area comes from those who accept the backdrop of evolutionary psychology (Buss, 2011). This argument generally referred to as "the Stone Age brain argument" contends that the evolutionary past of Homo sapiens produces limits and constraints on human behavior due to adaptive behaviors that have accrued over millennia. The foundational work for this perspective comes from Buss's (2011) achievements in the field of evolutionary psychology. Scholars in other fields have also taken on this mantle. For example Steven Pinker (2002) makes reference to the Stone Age brain and how it influences human behavior. Perhaps the most preeminent scholar supporting this perspective is E.O. Wilson (1998, p. 226) who refers to the complexity gap in this manner when referring to the human brain as "... a stone age organ evolved over hundreds of millennia and only recently thrust into the alien environment of industrialized society." In short, one can view our evolutionary past as a hindrance to the evolution of complexity itself.

Perhaps the most extreme example of evolutionary psychology's influence on contemporary scholarship is Nicholson's (2000) work. Nicholson argues that individuals within institutional environments are challenged by such evolved traits as dominance seeking, status hierarchies, quick judgments about others, and loss avoidance. Nicholson argues that these traits must be accepted as part of the human and organizational experience and also sees these attributes as inhibitors to change. To sum up, the Stone Age brain argument increases our recognition of the extent of human behavior that is hardwired. Clearly any understanding of the complexity gap must be appreciative of the insights from evolutionary psychology.

Naturally scholars in other disciplines have also tried to explore the complexity gap. The psychologist, Kegan (1994), without using explicit references to the complexity gap, argues that the modern project itself creates challenges for the individual that are difficult to match. Kegan sees the multiplicity of conflicting roles the individual must command in modern society as placing the individual "in over his head." Kegan views the modern individual as in over his head not only within the personal realm concerning issues such as parenting and marital relations, but also with the expectations of a knowledge-based workplace. Kegan argues, for example, that we must own our own work, be self initiating, possess state-of-the-art knowledge, and understand how we fit into the larger goals of the systems we support.

One could perhaps extend Kegan's argument to some of the common expectations one finds for employees in the literature of business management. This literature suggests that there are even more roles to be played when considering the organizational settings of life. Employees must be strategic, they must know when to follow, they must know when to lead and they must be prepared for change. We find ourselves in a world in which the demands placed on us require that only a Nietzschean like Ubermensch may be capable of meeting these challenges. This means that the individual's ability to match the challenges of increasing complexity is overwhelmed by the necessity of the protean behavior required to fit into the complex patchwork that is the modern project.

The literature of leadership studies also informs us about the challenges of the complexity gap. Van Vugt's (2012, p. 166-7) evolutionary, biological and psychological exploration of leadership results in what he calls the "mismatch hypothesis". In this case, Van Vugt notes that human leadership capabilities simply cannot keep pace with the rapidity of change in the current era of rapid and increasing complexity. Van Vugt's argument is 
particularly salient given the importance of leadership in the human experience, to human institutions and perhaps to the survival of the species. If leadership cannot keep pace with increasing complexity then the chances of reducing the complexity gap become fainter.

Social theorists also inform us of the deep influences of the complexity gap. For example, Rosa's (2013) recent effort to build a social theory of modernity explores the acceleration of technological, cultural and institutional changes. Rosa refers to the pace of change in the modern world as resulting in "contraction of the present" (p. 76) in which past knowledge and expectations may have very little influence and benefit for responding to and understanding current challenges and expectations. The world is simply moving faster than any of us have the ability to learn. Lessons from one stage of life may not apply to later stages. Without the comfort of stable expectations, people are situated in an anomic state that leaves little comfort and reliability. As Rosa notes, "social acceleration" (p. 15) simply outstrips the capacity of anyone individual to keep up leaving us in a condition he labels the "frenetic standstill" (p. 15).

We can thus see at the individual level of analysis that scholars from a variety of fields are appreciative of the complexity gap. Whether the gap is in part due to the hardwired nature of human behavior or due to the environment itself, contemporary human beings find themselves in a condition in which both our fixed and dynamic capacities are inadequate to keep pace with the world that evolves faster than our consciousnesses or abilities.

\section{Institutional Level}

At the institutional level scholars have for at least 40 years (Bennis, 1973) recognized that industrial age bureaucracy lacks the flexibility and dynamism requisite to match the postindustrial challenges of increasing complexity. In fact one could argue that much of the scholarship in fields such as management and organizational theory over the last 40 years have largely focused on attempting to deal with this one critical issue. As a question this issue becomes how do we create organizations and situate humans within those organizations in a manner that allows those organizations to adjust, to adapt and respond to a rapidly changing environment?

Perhaps the best appreciation of the institutional level challenges produced by the complexity gap is presented by W. Ross Ashby's (1956) notion of "requisite variety." Ashby's notion is a system's theoretical argument that simply states that systems must be able to "absorb" the variety of their environment. This perspective is taken to assume that the variety within an institution must be able to match the variety of its environment. While we are living in a time when we do see genuine change in institutions, for example the marriage institution in the United States, most of our institutions struggle to keep pace with the rapidly changing world.

It is clear though that human institutions, just as do individual human beings, have great difficulty coping with the rapidity of change and increasing complexity in the contemporary era. Thus a complexity gap affects individuals and institutions. We seem to live in the historical era in which industrial age institutions have difficulty meeting many of the challenges of postindustrial complexity. Perhaps unfortunately, institutions take on a sacred value. The problem with such sacred values however is that they tend to linger even when their legitimacy can no longer be maintained. Perhaps the reality of the need for and longevity of 
human institutions, especially in the contemporary world, is best exemplified in these comments by Csikszentmihalyi (1993):

A good society, one that encourages individuals to realize their potential and permits complexity to evolve, is one that provides room for growth. Its task is not to build the best institutions, create the most compelling beliefs, for to do so would be to succumb to an illusion. Institutions and beliefs age rapidly; they serve our needs for a while, but soon begin to act as brakes on progress. (p. 276)

\section{The Individual and Institutional Problem Nexus}

The challenge then for institutions is to meet Ashby's requirements of absorptive capacity to accept new information combined with feasible responses. Consider just a few of the social changes and new information that have already and will likely continue to influence institutions in the United States. The revolution in health care in the $20^{\text {th }}$ and $21^{\text {st }}$ centuries has markedly extended life spans in the developing countries. In the year 1900 the average lifespan of a U. S. citizen was 47 years of age. Currently for both men and women life spans push 80 years. This reality brings into question pre-existing institutions such as retirement. A work life starting at 22 carrying on for the industrial age model of 30 years would give a retiree almost 30 years of retirement. This appears as a considerable waste or at least misuse of human capital during the retirement era. And, consider that during the $20^{\text {th }}$ century scientific advancements increased life spans in the developed world by 30 years. While there likely is some biological limit to human longevity it is not unthinkable to see the average longevity of citizens in developed countries push 90 years of age in a not too distant future. Meeting the challenges of aging yet with an increasingly competent cohort of older citizens produces great challenges for governmental, business and nonprofit organizations.

Developments in the neurosciences also suggest a rethinking of existing institutional arrangements. It is generally agreed now by neuroscientists that the human brain does not reach full maturity for both men and women until approximately the age of 25 or 26 (Klingberg, 2009). Yet, deep institutional, familial and organizational rituals treat the age of 18 as a legitimate age for making many challenging life decisions. Given that the brain does not mature until age 25 one must ask why we as a society continue to hold the age of 18 as sacred. Recognizing that brain maturation does not occur until age 25 makes many of the responsibilities placed on 18-year-olds seem out of place and devoid of scientific foundation. For example, does it really make sense to ask an 18-year-old, whose brain is not fully developed, to make career decisions? In short, we as a society have chosen and those choices are reflected in our institutional arrangements to allow people with immature brains to make some of the most challenging life decisions concerning work, marriage and even fighting in wars.

The two developments noted above, increasing longevity and the recognition of the age of brain maturation, exemplify the challenges of attempting to reduce the complexity gap both at the individual and institutional levels. While it is now possible for people in developed societies to live comfortable and intellectually stimulating lives well into their 80 s we continue to maintain that 18 years of age adequately prepares a person to make difficult life decisions in a world of rapid change. This reality provides a stark recognition of how runaway complexity 
challenges our fundamental institutions. In a world in which 47 years of age was the average age of the person at death perhaps 18 years of age made sense as an age of majority. But does 18 years of age make sense in a world in which an individual may live well beyond 80 , have perhaps 50 years of work life, and reside in the world of increasing change in the technological and cultural milieus? Consider also the lingering influences of a world in which life was much shorter for the great mass of humanity. The U.S. constitution allows a person of age 35 to serve as president. How many readers of this journal would be comfortable with a 35 year old serving as the most powerful person in the world? In the age of monarchy such notions were, perhaps, sensible. Under the conditions of our current "late modernity" placing the world in the hands of a 35 year old appears quite troublesome.

\section{Expanding the Period of Nurturance}

Among mammals, and particularly the higher primates, humans are distinguished by having the longest period in which children are parented and remain within a nuclear family. This reality is of course generally associated with the more complex brains of humans and the complexity of human societies that require an extended period of nurturing and learning for adaptive success. Choosing the age of 18 as the age of majority is a historical artifact based on largely agricultural era values. Thus, an agricultural age notion of the proper age of majority continues to dominate institutions and expectations for young people in an historical era in which they may possibly live well into their 80s and perhaps 90s. In an era of rapid change, with accelerating change even more likely, is it sensible to assume that 18 or perhaps even 22 years of nurturance is adequate in which people may live well into their 90 s?

There is increasing evidence that the window between ages 18 and 26 represents an important frame in the development of the brain and thus in human decision-making skills (Mientka, 2013). Consider for example that if marriage is delayed until both partners are age 26 or older such marriages are much less likely to end in divorce than marriages in which both partners are age 20 or 22 at the time of marriage. Criminality, especially among males, also peaks between ages 15 and 26. The current general assumption among neuroscientists is that the frontal cortex in the brain is associated with executive control, in short, decision-making and impulse control is still within the developmental stage in this 18 to 26 years of age window.

Reducing the complexity gap suggests that we strongly reconsider 18 as the age of majority. In short, why not give the maturing brain a chance to develop to maturity before that brain is asked to make the decisions of a mature person? By extending the age of nurturance to age 25 or 26 we provide young people with an extended period of maturation and growth before they are expected to function well in a rapidly changing and increasingly complex world. Increasing the age of majority thus allows us to reduce the gap between the assumed youthful maturation and the end-of-life. Assuming that age 18 satisfies the requirements for mental maturity denies what we know scientifically but again reinforces the notion of how stable institutions reduce the opportunity to reduce the complexity gap.

The logical extension of extending the age of maturity demands a rather radical transformation of our views of education and the educational system. The current industrial age model of education particularly in the United States intends to produce students capable of coping with some of the minimal challenges of citizenship and with functioning within the 
economic system. While both K-12 education and university education attempt to develop curricula and classroom technologies that enhance student preparedness these efforts are constrained by the biological reality of how the human brain develops. The traditional model still hopes to develop individuals and prepare them for institutional life when their neuronal circuitry is not fully developed. The agricultural era model of education was perfectly suitable for the challenges of its time but as with other institutions has outlived its value and demands considerable rethinking.

One of the questions that arises when presenting such a radical model concerns which elements of the confluence of individual attributes will benefit from the extension of the period of nurturance. On the cognitive side of the ledger extending the age of nurturance into the educational system will allow the developing brain of young people to continue to grow and mature intellectually through its peak of age 25-26. Consider for example how poorly US students fare relative to their international counterparts in mathematics skills. Perhaps slowing down and allowing more time for some skill sets such as math will allow more students to better handle the challenges of math and enhance overall human capital.

The emotional development of individuals could also be better managed by extending the period of nurturance. Neuroscience research increasingly shows that the ages of 18 through 26 are very important periods for emotional maturation. Allowing young people to develop greater emotional maturity within the confines of an expanded educational setting may enhance individual well-being while improving professionalism and decision-making in the workplace. We can begin to see then that extending the period of nurturance may provide both cognitive and emotional benefits for the individual.

One continuing concern with such an approach involves what must be done with the genuine exceptional outliers. Current efforts for exceptional students to take advanced classes in high school or to track them into magnet schools may have some benefit. But exceptional intellect does not necessarily correlate with emotional development. In a hurried and rapidly changing world, hurrying anyone may be of little value. Extending the period of nurturance does not negate the need for individual attention in a postindustrial model of institutions responding to the individual needs of people. But what is needed are curricular supports and challenges that best respond to the intellectual and emotional development of the individual, given what we now know about the maturation of the brain.

Some immediate system level benefits would accrue by extending the period of nurturance. One possible benefit may accrue by delaying the age at which individuals enter labor markets. This approach would not only produce more mature and intellectually competent workers early in their career but would allow older workers to continue to work without over pressuring these labor markets. Enhanced systems of internship could also be developed allowing people ages 18 to 25 or 26 extended times to pursue varying options. Consider, for example, that only half of the individuals in the United States who hold a jurisdoctorate degree actually practice law. Clearly there are many factors as to why people do not engage in a chosen profession with high opportunity costs, but one explanation may simply be that the work is not as satisfying as a 22-year-old law school entrant might expect. While these years of 18 through 26 should be years of exploration we may also see stability in career 
choices. While such stability itself could be a problem in rapidly changing labor markets, at a minimum such important choices at a more mature age are likely to benefit everyone.

Working out the details of how such a radical model can be implemented requires more space than is provided in this article. I do not intend to depreciate the scope of the challenge involved. It is also important to recognize that most efforts to reduce the complexity gap will require the painstaking work of changing complex systems. Clearly changing embedded complex systems both politically and especially given the tight and loose connections of complex institutional networks requires considerable thought and time. While such efforts as advanced placement classes in high school and rethinking community college curricula are admirable, these efforts still suffer from an incremental approach to change that does little to reduce the complexity gap.

Anyone with a modicum of experience will naturally question the feasibility of this recommendation. Feasibility is of course a requirement for any dramatic request for change. There is however some evidence that experts in the field are beginning to see the need to rethink the age of majority relative to how the brain develops. Child psychologists in the United Kingdom are now arguing that adulthood be extended to age 25 (Mientka, 2013). Their argument is based on neuroanatomical development, emotional maturity and hormonal development. This approach then begins to take in the entire individual as we gain more knowledge about early adulthood and its problems and potentials. Naturally, moving from extending the age of majority to increasing the length of mandatory schooling represents an even more extensive challenge.

The Mental Wealth of Nations project (Government Office for Science, UK, 2008) established in the UK is a hopeful attempt to place brain health and intellectual development at the top of the national agenda. This project falling under the larger rubric of the Foresight Project (Government Office for Science, UK, 2008) is an attempt to get all institutions within the UK to better appreciate the development of the brain from infancy to senescence. This again is a whole systems effort to understand how forces ranging from familial factors to socialization and even nutrition affect brain health over the lifespan.

In the United States high school principals (NASSP, 2010) are calling for an extension of the age for mandatory schooling to age 18. These recommendations are founded on the usual arguments based on curtailing drop-out rates and the recognition that more education increases incomes. Inherent in these recommendations is the acknowledgment that the $21^{\text {st }}$ century demands more education for everyone if the complexity gap is to be reduced.

These occasional inklings of wisdom may naturally decay against the resilience of the status quo and the bureaucracies that maintain it. Changing cultural expectations by remedying the illusory notion that 18 is some magical number will also be a great challenge. Other challenges will also remain. Dealing with student outliers at both ends of the distribution will continue to challenge even a system that asks for formal education to extend to at least 22 years of age if not 26 years of age.

Let us assume a modest implementation of the recommendation proposed herein. Such a recommendation might still allow college education to end at approximately 22 years of age. The next obvious question concerns what is to be done with those ambitious 22 to 26-year-olds. One not yet mentioned point, is that not only does the brain mature at approximately age 26 but 
people also reach the peak of their working memory, quite often used as a proxy for general intelligence, at approximately age 26. This knowledge points to a conundrum, the challenge of ensuring that the human capital of 22 to 26-year-olds is used in a manner that is both individually and socially beneficial.

At the risk of pushing George Bernard Shaw's notion of dreaming "...things that never were" one possibility is to think of this group of 22 to 26-year-olds as the innovative class. A consortium of both government and private sector funding could be used to have this group of people work on important tasks of global and national import. Technologists could of course make their contributions. This would not be an unpaid internship but rather these individuals would be paid and of course their performance monitored. But why not use the enthusiasm and the periods of peak learning and working memory for individuals as a concerted and well tended national resource? On a more mundane level, this would allow 22 to 26-year-olds to develop the emotional maturity and technical aptitudes to produce the absorptive capacity required for an effective and engaged $21^{\text {st }}$ century mind.

One question that naturally arises concerns the nature of the projects 22 to 26-year-olds would be asked to explore. Possible areas of exploration for this new group of innovators would clearly have to include the notion of networks. A better understanding of the benefits and risks of globalization in a highly networked world (Goldin and Manathasan, 2014) may likely result in great benefits.

Appreciating the inherent nonlinearities of complex networks will provide this innovative class with improved knowledge of the uncertainty, risk and unintended consequences that extend beyond conventional assumptions about cause-and-effect. New methods of simulation combined with the growth of big data may be one means for better appreciating the challenges of complexity and globalization (Kiel \& McCaskill, 2012; Kiel, 2014; Room, 2011). At the same time such techniques must also be moderated by the reality that in the social realm, as Stuart Kauffman (in Clemens, 2014, p. xiii) notes, "Nothing flows ineluctably from anything."

Recent advancements in the study of human well-being may also serve to guide the educational agendas for the new innovative class. Clemens (2014) uses the United Nations Human Development Index (Malik, 2014) as one means for assessing the complexity of a contemporary nation state. The assumption here, of course, is that more complex nation states will possess the absorptive capacity to better survive and thrive in an increasingly complex world. The components of the human development index include life expectancy, mean years of schooling, expected years of schooling, and gross national income per capita. Beyond the obvious benefit of schooling identified by the development index the two substantive notions of life expectancy and gross national income provide guidance as to elements of the educational agenda for the innovative class.

While long life does not equate with a "good" life, increasing human longevity may include a multidisciplinary view of system level dynamics including environmental concerns, new developments in the biological and genetic sciences and the challenges of dealing with a population of older people who live far beyond the conventional notion of a work life. Creative thinking in these arenas would seem to provide intellectual explorations and practical solutions that would encompass the plethora of interests of those between the ages of 22 and 26. 
A focus on economic growth, in this case as noted by gross national income per capita, would allow the innovative class to consider and develop practical solutions for enhancing national and global economic growth. While a "good" life can be led without economic abundance (Dworkin, 2011), it is increasingly clear that economic abundance correlates with individual self-expression and the expansion of the human experience relative to lives of economic deprivation weighed down by tradition (Inglehart and Welzel, 2005).

It is increasingly evident that there is more to success than simply IQ. More concerted efforts must be made to develop emotionally resilient people capable of coping with a world of rapid and constant change. The literature on emotional intelligence (Goleman, 2000) provides support for this argument. More recently, Duckworth's (2013) work has identified "grit" as a critical element in student success. In other words, the ability to persist at a task in the face of distractions, temptations and frustration is now seen as essential for student success. Clearly the benefits of grit translate to many other arenas of life and particularly to facing the challenges of an increasingly complex world.

Efforts should also be devoted to what we know about human personality in the window between 22 and 26 years of age. Research on the Big Five personality types (Judge, Bono, Ilies \& Gerhardt, 2002) reveals that openness to new experience is a critical personality attribute that supports novelty and flexible responses to the challenges of an increasingly diverse world. While there is evidence that such personality attributes include a genetic component (Pinker, 2002) more should be done to ensure that students and youth in general have the opportunity to imagine a future of even greater variety and diversity. Another of the Big 5 personality attributes is conscientiousness. This attribute places a high value on dutifulness, order and control. While conscientiousness has its place, it is an element of an authoritarian mentality that often serves to reduce human flourishing and inhibit democratic decision-making. The cognitive closure associated with such authoritarian thinking oversimplifies the mosaic of reality. What is needed is a democratic mentality tolerant of diversity and accepting of its place in evolution and the human experience.

Finally, we must accept that there is risk involved in suggesting the development of such an innovative class of 22 to 26-year-olds. The reality of a complex and diverse world is that outcomes will differ contingent upon the dynamics of circumstances and thus our search for fairness and equity will perhaps always fall short of our ideals. This point is well made in the title of West's (2012) work Complex worlds: uncertain unequal and unfair.

The reality of inequality is not a suggestion for reinforcing greater inequality in a nation, group or perhaps even supranational system. The desire for hierarchy is rooted in evolutionary constructs related to status seeking behaviors that are deeply rooted in our evolutionary biology. Recent evidence suggests however that societies with relatively less economic inequality have citizens that fare better on almost every scale of social well-being (Pickett \& Wilkinson, 2009). So we must be wary that this new found innovative class does not become a ruling elite akin to Platonic philosopher kings.

\section{Conclusion}

Students of the sciences of complexity understand that the future is uncertain. The imaginary bifurcation diagram of the future represents multiple possible futures. These possible futures 
may enhance human well-being and flourishing or such futures may drive humanity to a dark and uninspiring future. The evolution of complexity produces diversity and thus we can generally expect a mix of both flourishing and mere subsistence in the human mosaic.

Some scholars (Gray, 2007) question the entire notion of human progress and question those of a teleological worldview who see some necessary end or goal to the human experience. While this view concerning teleology is largely correct, the human drama suggests multiple possible outcomes. At the same time, the last 100 years of human experience reveals tremendous strides in the proportion of the human population living materially satisfying lives in which free time affords humans the opportunity to flourish (Seligman, 2011) and develop in ways unforeseen in the past. Perhaps the extreme optimistic view argues that humans may be able to develop some type of optimal functioning (Sheldon, 2004). Reality will, of course, likely result in a state of affairs that is a mix of both challenging and perhaps violent elements consistent with our evolutionary past and the higher angels of our nature consistent with the neocortex in the multiple pathways for empathy (Baron-Cohen, 2011) that exist in the brain.

A large-scale change such as that presented here especially when fundamental human institutions are involved necessarily raises great fear (Hankiss, 2001). It is also clear however that the muddling through of incremental change will likely not resolve or help to close the complexity gap. For example, the notion that online learning with all of its weaknesses and strengths will somehow help us change the complexity gap is likely ill-fated thinking. Complexity must be matched with complexity. Our improved understanding of the nature of the maturing brain in our species requires that we rethink at a grand level how we educate. Just as universal education was once seen as an impossible dream, we must now consider another dream based on contemporary scientific foundations. Understanding and treating the maturing brain with greater respect may help us to push the bifurcation diagram of the human future in a positive direction that enhances both the human experience and the prospects for the survival of our species.

Finally, it must be recognized that the complexity gap cannot be closed but rather can only be reduced. An evolving reality that changes and produces complexity faster than can individuals or institutions appears now as a fundamental condition of late modernity. Perhaps, at the most basic level, what will be needed for the extension of the period of nurturance will be leadership that appreciates that education is a complexity-absorbing and complexity-creating social subsystem. Leadership is needed that accepts the risk and uncertainty in a world in which incrementalism has its place, but in which transformation may be required.

\section{References}

Ashby, W. (1956). An introduction to cybernetics. London: Chapman \& Hall.

Baron-Cohen, S. (2011). The science of evil: On empathy and the origins of cruelty. New York: Basic Books.

Bennis, W. (1973). Beyond bureaucracy: Essays on the development and evolution of human organizations. New York: McGraw-Hill.

Buss, D. (2011). Evolutionary psychology: The new science of the mind (4 $4^{\text {th }}$ Edition). Upper Saddle River, New Jersey: Pearson.

Clemens, W. (2014). Complexity science and world affairs. Albany, NY: SUNY Press.

Csikszentmihalyi, M. (1993). The evolving self: A psychology for the third millennium. New York: Harper Perennial. Duckworth, A. (2013). True grit. The observer, 26(4): 1-3.

Dworkin, R. (2011). Justice for hedgehogs. Cambridge, MA: The Belknap Press. 
Gazzaniga M., Doron, K. \& Funk, C. (2010). Looking toward the future: Perspectives on examining the architecture and function of the human brain as a complex system. In M. Gazzaniga (Ed.), The cognitive neurosciences $I V$ (pp. 1245-1252). Cambridge, MA: The MIT Press.

Goldin, I. \& Manathasan, M. (2014). The butterfly defect: How globalization creates systemic risks, and what to do about it. Princeton, NJ: Princeton University Press.

Goleman, D. (2000). Working with emotional intelligence. New York: Bantam Books.

Government Office for Science, United Kingdom. (2008). Mental capital and well-being: Making the most of ourselves in the 21 century. Retrieved from https://www.gov.uk/government/publications/mental-capitaland-wellbeing-making-the-most-of-ourselves-in-the-21st-century

Gray, J. (2007). Black mass: Apocalyptic religion and the death of utopia. London: Farrar, Strauss and Giroux.

Hankiss. E. (2001). Fears and symbols: An introduction to the study of western civilization. Budapest: CEU Press.

Inlgehart, R \& Welzell, C. (2005). Modernization, cultural change, and democracy: The human development sequence. New York: Cambridge University Press.

Judge, T., Bono, J., Ilies, R. \& Gerhardt, M. (2002). Personality and leadership: A qualitative and quantitative review. Journal of Applied Psychology, 87(4), 765-780.

Kegan, D. (1994). In over our heads: The mental demands of modern life. Cambridge, MA: Harvard University Press.

Kiel, L. (2014). The evolution of complexity studies in public administration. Complexity, Governance and Networks, 1(1), 71-78.

Kiel, L. \& McCaskill, J. (2012). Cognition and complexity: an agent-based model of cognitive capital under stress. In S. Banerjee (Ed.), Chaos and complexity theory for management: nonlinear dynamics ( pp. 254-268). Hershey, PA: IGI Global.

Klingberg, T. (2009). The overflowing brain: Information overload and the limits of working memory. New York: Oxford University Press.

Malik, K. (2014). Human development report 2014. Sustaining human progress: Reducing vulnerabilities and building resilience. New York: United Nations Development Programme.

Mientka, M. (2013). Adulthood extended to age 25 by child psychologies in UK. Medical Daily.com. Retrieved from http://www.medicaldaily.com/adulthood-extended-age-25-child-psychologists-uk-257835

National Association of Secondary School Principals. (2010). Raising the compulsory school attendance age. Retrieved from http://www.nassp.org/Content.aspx?topic=Raising the Compulsory School Attendance Age Proposed

Nicholson. N. (2000). Executive instinct: managing the human animal in the information age. New York: Crown Business.

Pickett, K. \& Wilkinson, R. (2009). The spirit level: Why greater equality makes societies better. New York: Bloomsbury Press.

Pinker, S. (2002). The blank slate: The modern denial of human nature. New York: Penguin Books.

Room, G. (2011). Complexity, institutions and public policy: Agile decision-making in a turbulent world. Cheltenham, UK: Edward Elgar.

Rosa, H. (2013). Social acceleration: A new theory of modernity. New York: Columbia University Press.

Seligman, M.. (2011). Flourish: A visionary new understanding of happiness and well-being. New York: Free Press.

Sheldon, K. (2004). Optimal human being: An integrated multi-level perspective. Mahwah, NJ: Lawrence Erlbaum.

Van Vugt, M. (2012). The nature in leadership: Evolutionary, biological, and social neuroscience perspectives. In D. Day, \& J. Antonakis, (Eds.), The nature of leadership (pp.141-175).Thousand Oaks, CA: Sage Publications.

West, B. (2012). Complex worlds: Uncertain unequal and unfair. Castroville,TX: Black Rose Writing.

Wilson, E.O. (1998). Consilience: The unity of knowledge. New York: Alfred A. Knopf, Inc. 
About the Author

L. Douglas Kiel is Professor of Public Affairs and Administration at the University of Texas at Dallas. Doug is a leading authority on governmental and management applications of the sciences of complexity. His current research interests include the neuroscience of leadership and applied efforts to produce simulators for managing organizational complexity. Kiel's research is cited in more than 120 journals ranging from fields as diverse as economics, to music, to nuclear science. Email: dkiel@utdallas.edu

(C) Copyright 2014. The author, L. DOUGLAS KIEL, assigns to the University of Alberta and other educational and non-profit institutions a non-exclusive license to use this document for personal use and in courses of instruction provided that the article is used in full and this copyright statement is reproduced. The authors also grant a non-exclusive license to the University of Alberta to publish this document in full on the World Wide Web, and for the document to be published on mirrors on the World Wide Web. Any other usage is prohibited without the express permission of the authors. 